\title{
INNOVATION, TECHNOLOGY ADOPTION AND EMPLOYMENT: FINDINGS ROM EVIDENCE SYNTHESIS
}

\author{
Mehmet Ugur \\ Department of International Business and Economics \\ University of Greenwich Business School \\ Park Row \\ London SE10 9LS \\ Email: M.Ugur@gre.ac.uk
}

\begin{abstract}
Researchers, policymakers, trades unions and employees are all interested in the employment effects of innovation and technological change. This interest has generated a long-standing debate and a rich set of theoretical and empirical findings. Because the innovation-employment relationship is conditional on innovation and skill types and a wide range of compensation and displacement mechanisms, reported findings have remained varied. This chapter draws on meta-analysis and mixed-method systematic review evidence to establish where the balance of the evidence lies and what explains the heterogeneity therein. After controlling for publication selection bias, the 'average' effect of innovation on employment is positive but small; and conceals a high degree of heterogeneity. Other findings indicate that: (i) the effect on unskilled labor employment is negative and the adverse effect is more pronounced in developing countries; (ii) the job-creation effect is relatively smaller in innovation-intensive industries apart from the ICT industry; (iii) patented innovations are associated with a relatively smaller employment effect; (iv) the difference between the employment effects of product and process innovation is more evident in less developed countries; (v) job-creating effects tend to diminish over time; (vi) the structure of North-South and South-South trade is likely to accentuate the skill bias of technological change; and (vii) the effect of innovation on employment follows a U-pattern when plotted against employment protection legislation in OECD countries. The chapter concludes with a brief discussion on what these findings imply for future research and public policy debate.
\end{abstract}




\section{INNOVATION, TECHNOLOGY ADOPTION AND EMPLOYMENT: FINDINGS ROM EVIDENCE SYNTHESIS}

Published as: Ugur M. (2020) Innovation, technology adoption and employment: Evidence synthesis. In: Zimmermann K. (eds) Handbook of Labor, Human Resources and Population Economics. Springer. https://doi.org/10.1007/978-3-319-57365-6 2-1

\section{Introduction}

Innovation and technological change are considered as main drivers of economic growth in the long run. This is the case both in first-generation endogenous growth models (Romer, 1990; 1994) and second-generation Schumpeterian models with creative destruction (Aghion and Howitt, 1992; 2006). The effect of innovation on employment, however, is less amenable to firm conclusions for several reasons. First, innovation may drive growth and employment in the long run, but the adjustment process may be protracted and could lead to job losses in the short-to-medium run (Aghion and Howitt, 1992). There is also a wealth of evidence indicating that technological change may be skill biased (Acemoglu, 1998 and 2003; Berman, Bound and Griliches, 1994; Berman and Machin, 2000; Berman et al., 2005; Machin and Van Reenen, 1998). The balance between job creation for skilled labor and job destruction for unskilled labor may be negative, depending on the speed of skill upgrading and labor-market institutions. Furthermore, the type of innovation and technology adoption matters: while product innovation and product-oriented technology adoption are usually expected to have a positive effect on employment, process-oriented innovation and technology adoption are expected to have adverse effects on employment (Katsoulacos, 1986; Harrison et al, 2014; Edquist et al., 2001). Finally, firm conclusions become even more elusive when one takes into account the wide range of displacement and compensation mechanisms that determine the balance between jobcreating and job-destroying effects of the innovation on employment (Vivarelli, 2011; 2013; 2014).

The aim of this chapter is to establish where the balance of the evidence lies and what explains heterogeneity in the employment effects of innovation. Due to comparability issues and space 
limitations, however, this aim can be achieved only for a subset of the evidence base - namely the employment effects of innovation estimated from a derived labor demand model (DLDM). In this model, the demand for labor depends on innovation after controlling for wages and capital stock in general and four output in majority of the empirical work (see van Reenen, 1997). In the case of wage- or employment-share models, however, the dependent variable is usually the employment- or wage-share of skilled labor as a function of relative wages, the capital/output ratio and technological change (see, for example, Berman and Machin, 2000; Berman et al., 2005; Cirillo, 2014). Finally, in the innovation decomposition models, the outcome variable is employment but the latter depends on two measures of innovation: a binary variable that indicates whether the firm has introduced process innovation and the number of new products as a proxy for product innovation (see, for example, Harrison et al., 2008; 2014). Given these specification differences discussed in Ugur et al. (2018), the evidence from the latter sources will not be examined systematically. Nevertheless, a summary of these theoretical models, together with recent models of routine-biased technological change will be provided in section 2 below.

There are several reviews of the literature on employment effects of innovation and technological change in both developed and developing countries (Pianta, 2004; Piva, 2003; Spiezia and Vivarelli, 2002; and Vivarelli, 2011, 2012, 2013 and 2014). These narrative reviews offer three general conclusions. First, the employment effect of technological change is contingent on a range of moderating factors, including labor market flexibility, product market competition, types of innovation, and international trade. Second, process innovation is more likely to be associated with job destruction whereas product innovation is more likely to be associated with job creation. Finally, the effect is more likely to be negative when the data relates to unskilled labor.

With respect to moderating factors, the narrative reviews suggest that the positive relationship between innovation and employment is more likely to be reported as positive when $R \& D$ and/or product innovation are used as proxies for technological change and when the data is related to innovation-intensive firms and industries (Vivarelli, 2014). In contrast, process innovation is reported to have a negative effect on employment and the adverse effect may be exacerbated as trade openness increases (Spiezia and Vivarelli, 2002; Piva, 2003; Pianta, 2004). A third conclusion is that labor market flexibility is usually associated with positive or less adverse innovation effects on employment (Benavente and Lauterbach, 2008). Finally, the 
effect of innovation and technological change on the demand for skilled (unskilled) labor is more likely to be positive (negative).

This chapter aims to contribute to existing reviews along four paths. First, it reviews published and unpublished work (i.e., journal articles and book chapters as well as working papers, reports or $\mathrm{PhD}$ theses) to avoid reviewer-induced selection. Secondly, it synthesizes the evidence from two strands of the literature through: (i) a meta-analysis of the relatively more visible work that reports estimates from the derived labor demand (DLDM) with data from developed and developing countries; and (ii) a mixed-method synthesis of the relatively less visible work that focuses on technology adoption and employment in low-income and lowermiddle-income countries (LMICs). Third, it addresses the issue of publication selection bias that arises when researchers tend to publish 'significant' evidence more often than otherwise with a view to support a preferred hypothesis. Finally, it provides both quantitative and qualitative assessment of how moderating factors (e.g., innovation type, skill type, innovation intensity in the industry, institutional quality, international trade, data period, model specification, estimation methods, etc.) affect the relationship between innovation/technological change and employment. Congruity between meta-analysis and mixed-method findings would allow for 'firmer' conclusions about where the balance of the evidence lies and how the employment effect may vary by the type of the moderating factors. On the other hand, discrepancies between the findings from two exercises would indicate the need for further research and verification, which meta-analysis research aims to encourage in any research field.

The rest of the chapter is organized as follows. Section 2 provides a summary of the theoretical models on technological change and employment. The section aims to take stock of the modelling effort and distil some implications for future research. Section 3 presents metaanalysis evidence based on 570 estimates from 35 primary studies that estimate a DLDM. It reports that: (i) the average employment effect of innovation and technological change is positive but small; (ii) the effect is highly heterogeneous; (iii) observable sources of heterogeneity include skill type, measure of innovation, innovation intensity of the firm/industry, estimation methods, inclusion/exclusion of output from the DLDM, lag length between innovation and measured effect on employment, and country characteristics (e.g., labor-market regulation). 
Section 4 provides meta-analysis evidence from 12 empirical studies reporting 180 estimates and a narrative synthesis of the qualitative evidence from 43 studies on lower-middle-income and low-income countries. Mapped evidence from both sources indicates that: (i) the 'average' effect in the full sample is not different from zero; and (ii) the effect of product innovation is larger than that of process innovation in sub-samples. There is also qualitative evidence indicating that international trade, weak forward and backward linkages, and weaknesses in governance and labor-market institutions tend to weaken the job-creating effects of technology adoption. Section 5 distils conclusions informed by the findings and identifies some implications for policy and future research.

\section{Technological change and employment: Competing models}

This chapter synthesizes the evidence on the employment effects of technological change based on a DLDM (van Reenen, 1997; Chenneles and van Reenen, 2002). The latter draws on an industry-level production with perfect competition, constant returns to scale (CRS) and a constant elasticity of substitution (CES) between capital and labor, as stated in (1) below.

$Y=T\left[(A L)^{(\sigma-1) / \sigma}+(B K)^{(\sigma-1) / \sigma}\right]^{\sigma /(1-\sigma)}$

Here, $Y$ is output, $L$ is employment, and $K$ is capital stock. Of the technology parameters, the Hicks-neutral technological change $(T)$ leaves the relative factor shares constant for a given capital-labor ratio $(K / L)$ ratio; the Harrod-neutral technological change $(A)$ is labor-saving and leaves the relative factor shares constant at any capital-output $(K / Y)$ ratio; and the Solowneutral technological change $(B)$ is capital-augmenting and leaves relative factor shares constant at any labor-output $(L / Y)$ ratio. The constant elasticity of substitution is $\sigma$ and lies between 0 and $1(0<\sigma<1)$.

Assuming perfect competition and hence equality of real wages $(W / P)$ with the marginal product of labor, the level of employment $(L)$ that maximizes productivity is as stated in (2) below.

$\log L=\log Y-\sigma \log (W / P)+(\sigma-1) \log A$ 
From (2), the elasticity of employment with respect to labor-augmenting technology $(\partial \log L / \partial \log A)$ is:

$\frac{\partial \log L}{\partial \log A}=\left(\frac{\partial \log Y}{\partial \log P}\right)\left(\frac{\partial \log (W / P)}{\partial \log A}\right)+\sigma-1$

The first term on the right-hand side is price elasticity of demand, whilst the second term is the elasticity of the real wage with respect to labor-saving technology $(A)$. Given that the elasticity of substitution $(\sigma)$ is between 0 and 1 , the effect of labor-saving technology $(A)$ on labor demand $(L)$ depends on the price elasticity of output $\left(\frac{\partial \log Y}{\partial \log P}\right)$ and the elasticity real wage with respect to labor-saving technology $\left(\frac{\partial \log (W / P)}{\partial \log A}\right)$. If the absolute value of the product of these elasticities is larger (smaller) than $(\sigma-1)$, an increase in technological change is conducive to an increase (decrease) in the demand for labor.

The DLDM is the empirical counterpart of this framework and can be stated as:

$\log L=(\sigma-1) \log (A / B)-\sigma \log (W / P)+\log K+\sigma \log R$

In (4), capital $(K)$ satisfies the condition of profit maximization, given the cost of capital denoted with $R$. Replacing the unobserved technology variables ( $A$ and $B$ ) with an appropriate measure of technological change, and assuming that the cost of capital is constant across industries but varies over time, the DLDM model estimated in majority of empirical studies can written as:

$\log L_{i t}=\gamma \log (\text { Tech_chnage })_{i t}+\beta_{1} \log (W / P)_{i t}+\beta_{2} \log K_{i t}+\tau_{t}+\varepsilon_{i t}$

where $i$ is industry; $\tau_{t}$ is a set of time dummies that capture the cost of capital over time; $\varepsilon_{i t}$ is a white noise error term; $\beta_{1}$ is the elasticity of labor demand with respect to real wage (which is equivalent to the elasticity of substitution between capital and labor); and Tech_change is a proxy for technological change. 
The skill share model (SSM) and the technology decomposition model (TDM) share a common ground with but also differ from the derived labor demand model (DLDM). Both are based on maximizing behavior under perfect competition. In the TDM (Hall et al., 2008; Harrison et al., 2008 and 2014), a firm is assumed to be producing two product types: old products produced with old technology $(j=1)$ and new or significantly improved products produced with new technology $(j=2)$. The firm is also observed in two different periods, $t=1$ and $t=2$. Outputs of old and new products in period t are denoted by $Y_{1 t}$ and $Y_{2 t}$, respectively. When $t=1, Y_{12}$ is zero because all products are old products. In period $t=2$, the firm may produce old and new products, represented by $Y_{21}$ and $Y_{22}$. Given this set-up, inputs in the production function are associated with technology types indexed by $j$ - as stated in (8) below.

$Y_{j t}=T * F\left(K_{j t}+L_{j t}+M_{j t}\right) e^{\left(\eta+\pi_{j t}\right)}$

Here, $T$ is Hicks-neutral technology; $K$ is capital, $L$ is labor, and $M$ is materials. The firmspecific fixed effect $(\eta)$ represents all unobservable factors that make a firm more (or less) productive compared to the average firm using the same technology. Finally, $\pi$ represents all unobservable shifts in the production function for reasons other than technological change, with an expected value of $E\left(\pi_{i t}\right)=0$. Employment growth in TDM is decomposed as follows:

$\frac{\Delta L}{L}=-\left(\ln T_{12}-\ln T_{11}\right)+\left(\ln Y_{12}-\ln Y_{11}\right)+\frac{T_{11}}{T_{22}} \frac{Y_{22}}{Y_{11}}-\left(\pi_{12}-\pi_{11}\right)$

Using small case letter to represent growth, the model can be re-written as follows:

$l=\alpha_{0}+\alpha_{1} d+y_{1}+\beta_{2} y_{2}+u$

Here $y_{1}$ and $y_{2}$ are rates of growth in output due to change in the production of old and new products, respectively. Parameter $\alpha_{0}$ is expected to have a negative sign and represents the relative inefficiency in the production of old product. Parameter $\alpha_{1}$ measures the effect of process innovation on employment, with process innovation measured as a binary variable $d$. The effect of output growth due to production of old products is captured by the unitary coefficient on $\boldsymbol{y}_{1}$. Finally, the effect of product innovation on employment is captured by $\beta_{2}$. 
The difference between the DLDM and TDM is the omission of wages in the latter. Wages disappear in TDM because the labor demand is determined by the production of old and new products taking wages as given. Furthermore, there are two measures of technological innovation: a binary measure for process innovation and new product count (or value) as a measure of product innovation.

The SSM (Berman et al., 1994; 1998 and Machin, 2001) also differs from the DLDM in two ways. On the one hand, it draws on a translog cost function as the dual of the production function. On the other, it relaxes the assumption of Hicks-neutral technology by assuming that the rate of substitution between inputs (i.e., capital and labor) is not constant across skill types. It derives the shares of unskilled $\left(S_{u}\right)$ and skilled $\left(S_{s}\right)$ labor in total cost (total wage bill) as follows:

$S_{u}=W_{u} L_{u} / T C=\alpha_{u}+\gamma_{u} \ln W_{u}+\theta_{u} \ln Y+\delta t$

$S_{s}=W_{s} L_{s} / T C=\alpha_{s}+\gamma_{s} \ln W_{s}+\theta_{s} \ln Y+\delta t$

Here $W$ is wage of unskilled and skilled labor, $T C$ is wage bill, $Y$ is output, and $t$ is time that represents technological change. Replacing the time-oriented technology measure with observable proxy for technology $(T)$ and assuming that capital $(K)$ is a quasi-fixed input, the wage shares can be rewritten as:

$$
\begin{aligned}
& S_{u}=W_{u} L_{u} / T C=\alpha_{u}+\gamma_{u} \ln W_{u}+\theta_{u} \ln Y+\beta_{1 u} \ln K+\beta_{2 u} T \\
& S_{s}=W_{s} L_{s} / T C=\alpha_{s}+\gamma_{s} \ln W_{s}+\theta_{s} \ln Y+\beta_{1 s} \ln K+\beta_{2 s} T
\end{aligned}
$$

Empirical work within the SSM framework (Berman et al., 1994; 1998 and Machin, 2001) tends to report that technological change is skill-biased in that technological innovation increases the demand for skilled labor at the expense of unskilled labor. The skill bias is usually confirmed with findings that indicate falling wage or employment shares for unskilled labor. Acemoglu $(1998,2002,2003)$ extend the theoretical framework for skill-biased technological change by demonstrating that the direction of technological change is endogenous. Whereas the technological change of the $19^{\text {th }}$ century was mainly skill-replacing, the increase in the skill pool (i.e., the increase in the number of graduates) has instigated a wave of skillcomplementary technological change from the second half of the twentieth century. Evidence 
to that effect consists of an initial fall in graduate earnings when the number of graduates increased significantly in the United states, followed by sustained increase in graduate earnings after the emergence of skill-directed technologies. Extensive reviews of the skill-biased technological change and its effects on employment are provided by Katz and Autor (1999), Goldin and Katz (2008, 2009); and Acemoglu and Autor (2011).

Recently, the routine-biased technological change (RBTC) literature has shifted the debate towards skill polarization instead of skill shares. The central argument is that technological change has become biased toward replacing labor in routine tasks. In other words, endogenous technology has entered a new wave of routine-biased instead of skill-biased technological change (SBTC). The hypothesis is that RBTC decreases the demand for middle- relative to high-skilled and low-skilled occupations (Autor, Levy, and Murnane 2003; Autor, Katz, and Kearney 2006, 2008; Goos and Manning, 2007; Autor and Dorn 2013). A recent work by Goos, Manning and Salomons (2014) develop a model to estimate the importance of RBTC and offshoring on job polarization. The authors report that the effect of RBTC is more important than offshoring. Also, RBTC explains not only overall job polarization but polarization within and between industries.

Nevertheless, Sebastian and Biagi (2018) have pointed out that RBTC models face some conceptual, operational, and empirical challenges. Conceptually, RBTC models define routine tasks as codifiable tasks that can be performed by machines. However, a measure of codifiability tends to be absent in databases usually used in empirical analysis. Furthermore, what may be perceived as routine for workers may not be so for machines. There are also indications of disconnect between the theoretical models and their operationalization. For example, routine task indices in the data sometimes include measures of quality controls, which do not reflect the theoretical definition. Similarly, whereas cognitive tasks are theorized to reflect problem-solving tasks, the corresponding indices often include measures of managerial responsibilities.

The brief review above indicates that the skill share models (SSMs) have been successful in opening new lines of empirical research on the relationship between technological change and employment. Nevertheless, the evidence informed by SSMs cannot be synthesized in this chapter because the outcome they explain is not comparable with the outcome estimated in the DLDM. In the former, the outcomes are either the share of skilled (or unskilled) labor in total 
employment (or wage bill), or the polarization of employment. These outcomes are not comparable with that of DLDM. Stated differently, the findings from both sets of models cannot pooled for meta-analysis.

\section{Meta-analysis evidence: All countries}

The evidence in this section is from Ugur et al. (2018), who utilize meta-analysis tools to synthesize the evidence on the relationship between innovation/technological change and employment. The meta-analysis is based on 570 effect-size estimates reported in 35 studies and each estimate is coded to establish how the effect-size varies by: (i) publication type (journal article, book chapter, working paper, etc.); (ii) model specification (whether the DLDM include or exclude capital and output, the data is in levels or growth rates, time/industry dummies are included, etc.); (iii) sample characteristics (country of origin for the data, whether the firm/industry is innovation-intensive, the data is panel or cross-section, and the firm is small or large.); and (iv) estimation methods (ordinary least squares, fixed-effects, and instrumental variable estimators such as general method of moments, two- or three-stage least squares).

The unit of measurement for the dependent and independent variables differs between (and even within) studies. To ensure comparability, the effect-size estimates are converted into partial correlation coefficients (PCCs). The PCC measures the strength of the association between technological change and employment, after taking account of other determinants of employment such as wages, capital and output. Its standard error represents variations due to sampling error. ${ }^{1}$ Ugur et al (2018) presents the included studies, with information on a range of study characteristics. ${ }^{2}$

Primary studies report multiple estimates, with a range between 2 and 105. Median PCCs (proxy for effect size) in $90 \%$ of the studies are positive Across studies, the median PCC and the associated t-value are 0.036 and 1.850 , respectively. Taken at face value, the summary measures indicate a positive relationship between innovation and employment on average.

\footnotetext{
${ }^{1}$ See Ugur et al. (2017) for further information on calculation of PCC and its standard error.

2 The majority of the studies are published journal articles (71\%), followed by working papers (26\%). While $74 \%$ of the studies utilised firm-level data, $14 \%$ utilised industry-level data, with the remainder using sector-level data.
} 
However, the summary measures conceal a high degree heterogeneity in the evidence base (see, Ugur et al, 2018).

Another drawback of the summary measures is that they may be affected by publication selection. The funnel graph in Figure 1 provides visual information about publication selection bias, reflected as funnel asymmetry around the fixed-effect average represented by the vertical line. It also indicates a high level of unobserved heterogeneity, captured by the number of observations beyond the $95 \%$ pseudo-confidence interval limits (dashed lines). The heterogeneity estimate from the random-effect meta-regression estimator proposed by Harbord and Higgins (2008) is $85 \%$ and confirms the visual evidence from the funnel graph.

\section{Figure 1: Innovation and employment: Funnel graph of effect-size estimates}

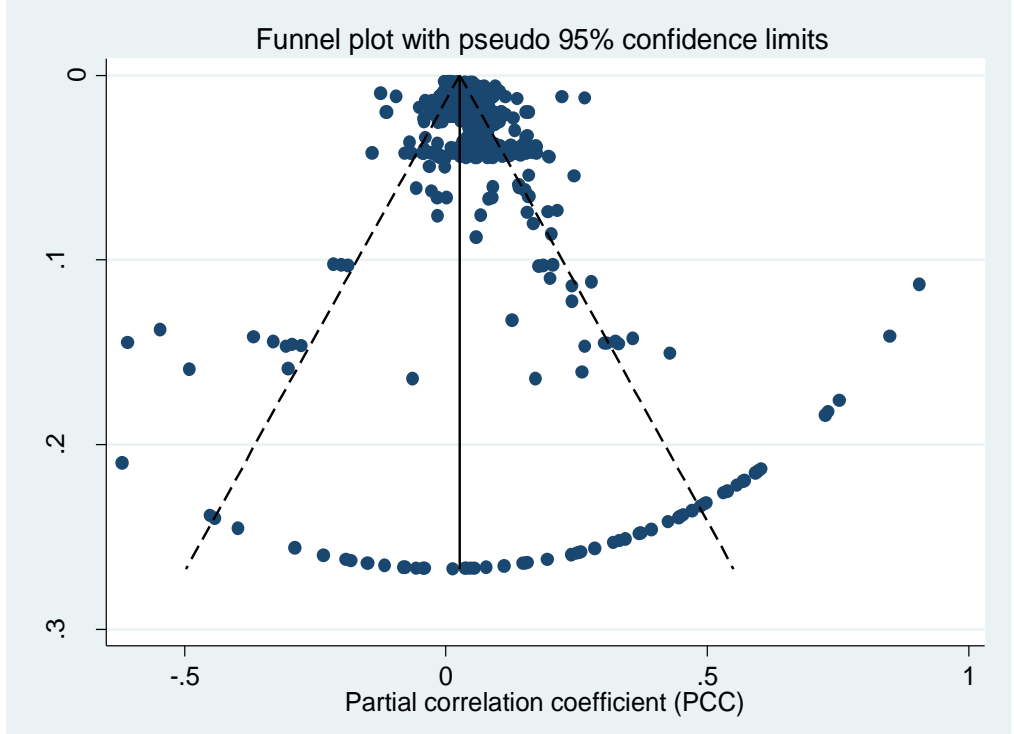

Excessive heterogeneity does not invalidate the summary measures obtained from the evidence base but makes them less generalizable to other contexts. However, when summary measures ignore the risk of selection bias they can lead to incorrect inference. This is common problem in narrative reviews that rely on vote counting or simple averages. That is why it is necessary to conduct meta-regression analysis to take account of selection bias and quantify the 
observable sources of heterogeneity. The meta-regression model informed by the selection process discussed in Egger et al. (1997) can be stated as follows: ${ }^{3}$

$P C C_{i}=\beta+\alpha S E_{-} P C C_{i}+u_{i}$

However, model (11) raises several estimation issues. First, the model is heteroskedastic because effect-size estimates have widely different standard errors. This issue is addressed by estimating a weighted least squares (WLS) version, where precision-squared $\left(1 / S E_{-} P C C_{i}^{2}\right)$ is used as analytical weights. This is equivalent to dividing both sides of (2) with the standard error (Stanley and Doucouliagos, 2014 and 2012; Stanley, 2008), leading to:

$t_{i}=\alpha+\beta\left(1 / S E_{-} P C C_{i}\right)+v_{i}$

Here $t_{i}$ is the t-value associated with the reported estimate and the error term $v_{i}$ is the error term in (11) divided with the standard error. Testing for $\alpha=0$ is a test for funnel asymmetry test (FAT) or publication selection bias. The bias is considered as substantial if $|\alpha| \geq 1$ or as severe if $|\alpha| \geq 2$ (Doucouliagos and Stanley, 2009; 2012) ${ }^{4}$. On the other hand, testing for $\beta=$ 0 is a 'genuine effect' or precision-effect test (PET) after controlling for selection bias. Doucouliagos and Stanley (2013) suggest that an effect size (PCC in this case) is small if it is less than \pm 0.07 . The PCC indicates strong association (large effect) if it is greater than \pm 0.33 , whilst a PCC in between indicates moderate effect.

The second issue is the nested nature of the meta-analysis evidence, where effect-size estimates are nested within primary studies due to within-study dependence on the same dataset or estimation method. The nested nature of the data implies that the publication-selection bias and the effect-size estimates may be subject to study-specific random effects. This issue is addressed by adopting a multi-level (hierarchical) modelling approach, where unobserved

\footnotetext{
${ }^{3}$ This meta-regression model has been applied and evaluated widely (see, Stanley, 2005 and 2008; Stanley and Doucouliagos, 2012). The underpinning theoretical framework is that of Egger et al. (1997), who postulate that researchers search across model specifications, econometric techniques and data measures to find sufficiently large (hence statistically-significant) effect-size estimates.

${ }^{4}$ Testing for selection bias is justified given the evidence about its prevalence in both social-scientific and medical research (Card and Krueger, 1995; Dickersin and Min, 1993; Ioannidis, 2005; and Simmons et al., 2011).
} 
study characteristics are modeled as random intercepts (RI) or random intercept and slopes (RIS). ${ }^{5}$ The bivariate meta-regression results are presented in Table 1.

Table 1: Technological innovation and employment: Effect-size estimates as PCCs - by innovation and skill type

\begin{tabular}{lcccccc}
\hline & & & & & & \\
Dependent variable: t-value & $(1)$ & $(2)$ & $(3)$ & $(4)$ & $(5)$ & $(6)$ \\
\hline Effect size (PCC) & $0.029 * * *$ & 0.004 & $0.037 * * *$ & $0.025^{* * *}$ & $0.004 *$ & $0.025^{* * *}$ \\
& $(0.008)$ & $(0.004)$ & $(0.007)$ & $(0.006)$ & $(0.002)$ & $(0.006)$ \\
Publication selection bias & $-1.405 * *$ & $1.895 * * *$ & 0.210 & $0.937 * * *$ & $0.712 * *$ & 0.461 \\
& $(0.683)$ & $(0.141)$ & $(0.378)$ & $(0.298)$ & $(0.287)$ & $(0.392)$ \\
& & & & & & \\
\hline Observations & 66 & 69 & 344 & 42 & 43 & 567 \\
Studies & 14 & 13 & 21 & 7 & 7 & 35 \\
Intra-study correlation (ISC) & $0.573 * *$ & N.A. & $0.38^{* * *}$ & $0.210^{* * *}$ & N.A. & $0.121 *$ \\
Estimator & HM2/RI & OLS & HM2/RI & HM2/RI & OLS & HM3/RIS \\
\hline
\end{tabular}

Notes: Column (1): process innovation and demand for mixed-skills labor; (2) product innovation and demand for mixed-skills labor; (3) undifferentiated innovation and demand for mixed-skills labor; (4) undifferentiated innovation and skilled labor; (5) undifferentiated innovation and demand for unskilled labor; (6) full sample. Estimators: OLS - ordinary least squares; HM2/RI - two-level hierarchical estimation with random intercepts; HM3/RIS - three-level hierarchical estimation with random intercepts and slopes. Robust standard errors are in brackets. Three observations with undue influence are excluded, using the DFBETA influence statistics. ISC indicates the correlation between estimate pairs within each study. *, **, *** indicate significance at $10 \%, 5 \%$ and $1 \%$, respectively. N.A.: Not applicable.

In Table 1, the average effect of all innovation types on employment (column 6) is positive but small (0.025). In fact, the effect remains small even when demand for skilled labor is estimated (0.025 in column 4). Also, the effect on the demand for unskilled labor (column 5) is too small to be practically significant (0.004). These findings are in line with conclusions reported in narrative reviews. However, and in contrast to narrative review and innovation decomposition findings, the effect of product innovation is statistically insignificant (column 2). Furthermore, the effect of process innovation (column 1) is positive and significant (0.029). These findings may well be due to small sample sizes (66 observations for process innovation and 69 for product innovation). However, findings from the multivariate meta-regression with the full sample (see below) also indicate lack of systematic difference between the employment effects of product innovation and other types of innovation.

\footnotetext{
${ }^{5}$ Discussion on other issues and the way in which they are addressed is in Ugur et al. (2017). It must also be noted that the choice between ordinary least squares (OLS) and hierarchical model (HM) estimations is made on the basis of likelihood ratio (LR) tests. The HM estimator is applied if the LR test rejects the null hypothesis that the OLS estimates is nested within (i.e., is consistent with) the HM estimate.
} 
With respect to publication selection, the bias is substantial in columns 1 (employment effect of process innovation) and column 2 (employment effect of product innovation). The bias is negative in the case of process innovation but positive in the case of product innovation. The signs indicate that researchers tend to report evidence in line with theoretical predictions more often than otherwise. Hence, after controlling for high levels of selection bias, the average effect becomes small or insignificant. ${ }^{6}$

Ugur et al. (2018) identified 28 moderating factors as potential sources of effect-size heterogeneity. These moderating factors reflect variations in innovation type, skill type, publication type, sample characteristics, model specification and estimation methods. The moderating factors are constructed as binary variables that take the value of 1 if the reported estimate is associated with a given characteristic (moderating factor) and zero otherwise. Definition and description of these moderating factors are presented in Ugur et al. (2018). Their influence on the average employment effect of innovation is estimated through a multivariate meta-regression model (a 3-level multivariate HM). In the model, all moderating factors are divided by the standard error of the estimate to capture their effects on the average effect-size estimate rather than the publication selection bias. Finally, the multivariate meta-regression model is estimated with different specifications for the standard error and with frequency weights for multiple estimates from the same study.

A positive (negative) and significant coefficient on the moderating variable indicates that the estimates of the innovation's employment effect are systematically larger (smaller) when they are associated with the moderating factor. If the coefficient is insignificant, the innovation's employment effect does not vary with the moderating factor. Non-significant moderating factors include: whether the estimate is reported in a journal article versus working papers or reports; inclusion of time/industry dummies, wage or capital in the DLDM; whether innovation is measured with $R \& D$; whether innovation type is product or process innovation, and whether the model is estimated with an instrumental variable (IV) estimator.

\footnotetext{
${ }^{6}$ The high levels of publication selection bias are observed despite the inclusion journal articles and non-journal articles such as working papers and reports. The evidence on whether selection bias is larger (or smaller) in journal articles is mixed. Costa-Font et al. (2013) put forward the 'winner's curse' hypothesis and report that journals tend to exploit the quality reputation of the review process and publish more selected evidence. On the other hand, Ugur et al. (2016a) report that R\&D productivity effect-size estimates published in journals are not larger than estimates published in working papers and report.
} 
Ugur et al. (2018) report that only two narrative review conclusions about sources of heterogeneity are supported by findings from the multivariate meta-regression analysis: (i) adverse effects of innovation on unskilled labor employment; and (ii) larger effect-size estimates in more recent primary studies (those published after 2000). Whilst the first lends support to the skill-biased technological change analyzed in the skill/wage share models of innovations (see, above); the second lends support to the observation by Vivarelli (2014) that increased availability and richness of datasets after 2000 may have contributed to estimating effects with higher precision.

However, there is evidence contradicting the narrative review conclusions with respect to four sources of heterogeneity. First, neither product nor process innovation is associated with systematically different effects on employment - both moderating factors are statistically insignificant in the multivariate meta-regression results. Secondly, estimates based on innovation-intensive firm/industry data in primary studies are relatively smaller than those associated with the reference category. The difference between the narrative review and metaregression findings is due to publication selection bias, which is controlled for in the metaregression but not in vote counting or simple average estimates that narrative reviews rely upon.

A third difference between meta-regression and narrative review findings is that, the effect of technological innovation on labor demand is dampened over time. This is in contrast to narrative review observations that worker displacement in the short run may be reversed as compensation mechanisms trigger new demand for labor in the long run. However, this finding is in line with the creative destruction argument in Schumpeterian models, where a given innovation becomes obsolete as competitors introduce new technology over time (Aghion et al., 2014). Finally, there is no systematic difference between the effect-size estimates based on $\mathrm{R} \& \mathrm{D}$ and other measures of innovations. This is in contrast to the observation in Vivarelli (2014) that the employment effect of innovation is larger when the latter is measured $R \& D$ investment, which tends to be oriented towards product development. Other findings from the multivariate meta-regression analysis are summarized below.

Inclusion of output in the empirical model is associated with smaller estimates compared to models that do not control for output. This may be because firm optimization implied by the theoretical model does not hold every period. Stated differently, firm/industry employment 
may be responding not only to capital and labor costs but also to demand shocks, the exclusion of which may be a source of omitted variable bias in estimates from the DLDM in some studies.

Role of patents: Technological innovation measured by intellectual property assets (IPAs) is associated with smaller estimates compared to all other measures of innovation. This finding can bridge the evidence gap for two reasons. First, it may indicate that the IPA counts may not reflect the true quality of the technological innovation they protect. Secondly, it raises questions about the inter-relationship between innovation, market power due to patent protection and employment. The finding indicates that innovation and employment models should be augmented with market power either by modelling the latter as part of the reduced form or as a separate process in a system of equations.

Employment in manufacturing industry: Innovation's effect on manufacturing employment is larger compared to non-manufacturing employment. This is despite the fact that the unit of analysis (firm versus industry) is distributed evenly between manufacturing and nonmanufacturing sectors. This finding provides somber reading in that manufacturing firms/industries that innovate register higher demand for labor compared to services, but the share of manufacturing in total employment is declining in OECD and non-EOCD countries.

OECD vs Non-OECD countries: There is evidence that the innovation's effect on employment is larger in OECD countries. There is also evidence indicating that the employment effects are larger in the USA compared to all other countries. This pattern suggests that innovation is more likely to be job-creating in developed countries compared to developing countries. However, it does not address the question as to whether the job-creation and job-destruction effects are associated with different levels of labor market regulations. This issue is probed below, where provide estimates from split samples of countries with different levels of employment protection.

High innovation intensity: Data based on firms/industries classified as highly innovative by primary-study authors is associated with smaller effect-size estimates. This is in contrast to frequent policy statements that jobs are created by firms/industries with high innovation intensity. The implication for future research is that it is advisable to investigate non-linearities in the innovation-employment relationship in the light of two recent work. The first reports an inverted-U relationship between innovation intensity and firm survival (Ugur et al., 2016). In 
this work, firms at the high end of the R\&D intensity have shorter survival times and tend to shed labor in the years before exiting. The second is Bogliacino (2014), who demonstrates that the elasticities of employment with respect to $R \& D$ investment are non-linear due to a combination of scale effects and decreasing returns to $R \& D$.

A final check for sources of heterogeneity is related to the mediating role of labor-market institutions in the relationship between innovation and employment. The role is investigated by estimating the average employment effect in six OECD countries ranked by the level of employment protection legislation (EPL): France, Sweden, Germany, Italy, UK, and US. Figure 2 below depicts the relationship between the country average effect and EPL level, which is obtained from OECD (Ongoing). In contrast to theoretical predictions that labormarket flexibility would augment the employment effects of innovation, the country-specific effects have a U-shaped relationship with EPL. The effect is relatively larger in France and Sweden at the high-EPL end and in the US at the lower-EPL end.

Figure 2: Effects of innovation on employment:

\section{By employment protection legislation (EPL) strength}

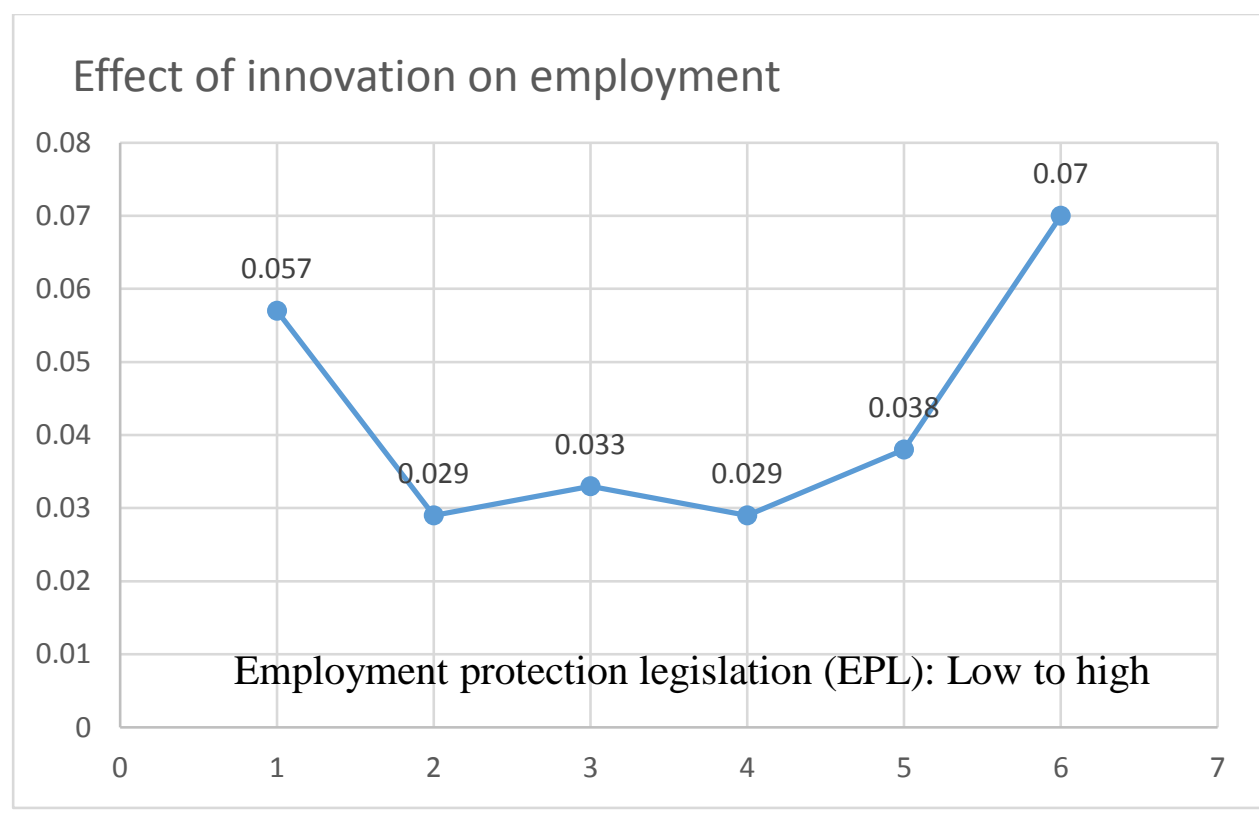

Note: 1 = USA; $2=\mathrm{UK} ; 3=$ Italy; 4 = Germany; $5=$ Sweden; and $6=$ France.

The U-shaped pattern indicates that labor-market flexibility may be high in both low-EPL and high-EPL countries. In low-EPL countries such as the USA, labor-market flexibility follows 
from relatively easier hiring and firing. In the high-EPL countries such as Sweden and France, however, labor-market flexibility result from labor unions' agreements to wage flexibility in exchange for avoiding job destruction. This interpretation is in line with non-linear relationships between labor-market regulation and employment reported by Calmfors and Driffill (1988) and Amable and Gatti (2004).

\section{Mixed-method evidence: Low-income and lower-middle-income countries (LMICs)}

The implications of technology adoption for productivity, income and welfare have been studied widely in the context of low- and lower-middle-income countries (LMICs). With notable exception of Piva (2003) and Vivarelli (2014), however, the relationship between technology adoption and employment in LMICs has largely remained below the radars of researchers and reviewers alike. This section is a partial attempt at closing the gap. It draws on a mixed-method systematic review by Ugur and Mitra (2017), which maps the qualitative and empirical evidence on the employment effects of technology adoption in LMICs. ${ }^{7}$

The mixed-method systematic review involves mapping qualitative and empirical evidence from primary studies that differ with respect to method (qualitative versus quantitative), context, and analytical framework (Harden and Thomas, 2005). It combines the strength of the narrative synthesis with those of meta-regression analysis. The strength of the narrative synthesis lies in: (i) accounting for how technology adoption affects employment, why and for whom; (ii) identifying causal mechanisms and deriving 'context-specific' conclusions; and (iii) identifying the range of displacement and compensation mechanisms at work. On the other hand, meta-analysis allows for obtaining reliable estimates for the effects of technology adoption in LMICs and how the effect vary by quantifiable moderating factors when the estimates are comparable. The meta-analysis findings are based on 12 quantitative studies, whereas the narrative synthesis findings are based on 43 qualitative studies presented Ugur and Mitra (2017).

In the LMIC context, the effect of process-oriented technology adoption on skilled-labor employment is positive and significant (Table 2, column 1). The effect is larger in the case of

\footnotetext{
${ }^{7}$ Empirical estimates from LMIC studies are also derived from a DLDM. Hence, they are comparable with the meta-analysis evidence discussed above. The difference between the two is twofold. On the one hand, the agriculture feature more often in LMIC studies. On the other, the link between the empirical and theoretical DLDM in LMIC studies is less systematic.
} 
product-oriented technology adoption and mixed-skill labor employment (0.397 in column 3). However, the effect on unskilled labor is insignificant, and this leads to an insignificant average effect in the full sample. The positive effect on skilled labor is in line with narrative reviews of the wider literature that include studies from developed and developing countries. Also, the positive effect of product innovation is in line with innovation-decomposition studies. However, it must be noted that the findings are based on a narrow evidence base, which consists of 33 and 25 estimates, respectively.

Table 2: Technology adoption and employment in LMICs

\begin{tabular}{lllll}
\hline & $\begin{array}{l}\text { Process-oriented } / \\
\text { Skilled labor }\end{array}$ & $\begin{array}{l}\text { Process-oriented } / \\
\text { Unskilled labor }\end{array}$ & $\begin{array}{l}\text { Product-oriented } \\
\text { / Mixed skills }\end{array}$ & Full sample \\
\hline Effect size (PCC) & $0.189^{* * *}$ & -0.025 & $0.397^{*}$ & 0.072 \\
& $(0.042)$ & $(0.027)$ & $(0.224)$ & $(0.109)$ \\
& & & & \\
Selection Bias & $-6.908^{* *}$ & $1.661^{*}$ & -4.031 & -0.022 \\
& $(2.888)$ & $(0.892)$ & $(3.654)$ & $(3.752)$ \\
\hline Observations & 33 & 93 & 25 & 180 \\
Studies & 3 & 9 & 4 & 12 \\
\hline
\end{tabular}

Ugur and Mitra (2017) estimate a multivariate meta-regression model to identify the sources of heterogeneity in the evidence base. They report that the effects of product-oriented technology adoption on employment are systematically larger than those of process-oriented or undifferentiated technology adoption. Also, the effects of technology adoption on unskilled labor employment are systematically smaller than those in the excluded category (skilled or mixed-skill labor Another finding is that technology adoption may not be strictly exogenous due to reverse causality in the relationship between technology adoption and employment, measurement errors or model misspecification. This is reflected in relatively smaller effectsize estimates obtained from IV estimators that take account of endogeneity.

The meta-analysis findings above are based on data for agriculture and manufacturing pooled together. The qualitative evidence on agriculture only indicates is that mechanization on its own tends to have a negative effect on farm employment. However, the effect tends to be positive when mechanization is accompanied by extension of the farm size and hiring of 
outside labor. ${ }^{8}$ With respect to labor type, mechanization is reported to reduce the employment of family labor and that of young farmers (Agarwal, 1981; Chopra, 1974); but it tends to increase the employment of seasonal labor and child labor (De Clerk, 1984).

A fourth finding is that mechanization tends to have a positive effect on employment when it is accompanied with product differentiation and strong forward/backward linkages between agriculture and manufacturing industries (Lalwani, 1992; Bhatia and Gangwar, 1981; Chopra, 1974; Inukai, 1970). Type of process-oriented technology adoption also matters: the effect on farm employment is more likely to be positive when it consists of introducing new feeds/fertilizers and irrigation techniques (Lalwani, 1992; Bhatia and Gangwar, 1981; Chopra, 1974). On the other hand, mechanization is associated with adverse effects when it is used for ploughing and harvesting operations instead of sowing and the farm size is large to begin with (De Clerk, 1984; Agarwal, 1981).

A fifth conclusion relates to the consequences of process-oriented technology adoption for onfarm/off-farm employment in the context of the Green Revolution (GR). In the short run, GR technologies are associated with uncertain employment effects. The long-run effect on on-farm employment is negative. The long-run effect on off-farm employment is positive when: (i) the demand for new products/services increases as a result of increased farmer income; and (ii) forward and backward linkages between farm and non-farm activities are strong.

Finally, some studies examine the role of institutions in the relationship between employment and technology adoption. One conclusion from this work is that institutional characteristics of the country and those of the labor markets determine the technology choice and hence the scope for employment creation (Annable, 1971; Fagerberg, 2010; Garmany, 1978; and Caballero and Hammour, 1996).

Mapping the meta-analysis and narrative synthesis, it can be concluded that the effect of technology adoption on employment in LMICs is uncertain at best. Job-creating effects are likely to dominate when: (i) skilled-labor employment is investigated; (ii) forward and

\footnotetext{
${ }^{8}$ These conclusions are based on evidence from: Chopra (1974) on farmers in 13 Punjabi villages in India; Bhatia and Gangwar (1981) on 965 small farms in Karhal district of India; Agarwal (1981) on 240 farms in India; De Klerk (1984) on 61 maize farms in South Africa; Inukai (1970) on rice farmers in Thailand; and Lalwani (1992) on dairy farming in India.
} 
backward linkages are strong; (iii) the evidence relates to India and China as opposed to other LMICs; and (iv) institutional quality is conducive to optimal technology choice, investment in skills and wage flexibility. On the other hand, job-destroying effects are more likely when: (i) new technologies are adopted to cater for the demand of high-income consumers; (ii) international trade is capital-intensive; and (iii) mechanization in agriculture is not combined with new irrigation systems and fertilizer use.

\section{Summary}

This chapter has provided meta-analysis and mixed-method evidence from two strands of the literature: (i) the relatively more visible work that reports estimates from the derived labor demand (DLDM) with data from developed and developing countries; and (ii) the relatively less visible work that focuses on technology adoption and employment in LMICs.

Meta-analysis of the evidence based on the DLDM indicates partial empirical support to two conclusions reported in prior reviews: (i) technological innovation increases the demand for skilled labor more than unskilled labor; and (ii) primary studies published after 2000 tend to report relatively larger 'effect-size' estimates. Other findings, however, does not lend support to a range of narrative review conclusions. This was evident with respect to the effects of process and product innovation on mixed-skills labor demand. The selection bias in these evidence pools is in the direction of theoretical predictions; and the level of selection is so high that the effect-size estimates turn out to be the smaller than simple summary measures that narrative reviews rely upon. Further findings also contradict the narrative review conclusion that the employment effects of innovation are larger in high-innovation-intensity firms or industries.

It must be indicated that the absence of support for skill bias and for larger employment effects from product innovation may be due to the small number of observations (primary-study findings). Therefore, they must be considered in conjunction with the mixed-method findings on LMICs. Both meta-analysis and narrative synthesis of evidence on LMICs indicate that the employment effects are larger when employment of skilled labor is the outcome variable and when product-oriented technology adoption is the independent variable. Given these findings, two conclusions may be stated: (i) more research is needed to verify the skill bias and the 
relatively larger employment effects from product innovation; (ii) skill bias and relative effects of product innovation may be related to the level of development, with larger skill bias and product-innovation effects more likely to be observed in less developed countries.

The meta-analysis findings also shed light on some moderating factors with respect to which the narrative reviews are either silent or inconclusive. Specifically, they indicate that: (i) the inclusion of output in the DLDM is associated with smaller innovation effects on employment; (ii) measuring technological innovation with $R \& D$ investment has no systematic effect on reported estimates, but the reported estimates are relatively smaller when innovation is measured with patents or trademarks and relatively larger when innovation is measured with investment in ICT; (iii) the effect of labor-market regulation on the relationship between innovation and employment follows a U shape - with larger innovation effects on employment in both high and low regulation countries.

On the other hand, the narrative synthesis of qualitative studies indicates that the employmenteffects of technology adoption are more likely to be positive when: (i) there are strong forward/backward linkages between innovative firms/farms/industries and their upstream or downstream counterparts; and (ii) governance institutions encourage and facilitate technology adaptation instead reliance on off-the-shelf technology only. In contrast, the employment effects are more likely to be small or negative when technology adoption is dependent on imported technology or geared to toward the production of goods/services for high-income groups in the country.

These findings indicate that policy statements that establish or suggest a positive and linear relationship between innovation/technological change and employment should be qualified. The effect is small and highly heterogeneous and likely to be skill-biased, particularly in the context of developing countries. To ensure that the employment-creation effect dominates the job-destruction effect, technology adoption should be combined with policies aimed at enhancing institutional quality and encouraging investment in skill upgrading.

With respect to future research, the findings presented above indicate the need for better-quality data on innovation. Chennelles and van Reenen (2002) provide an authoritative account of the difficulties involved in measuring innovation as a proxy for the unobservable technological change. Therefore, investment in better-quality data may be necessary to reduce the risk of mismeasurement. The transition to capitalization of $R \& D$ expenditures may be a step in the 
right direction because it will bring a common approach to $\mathrm{R} \& \mathrm{D}$ deflators and to the building of R\&D capital stock from R\&D investments. Also, it can be argued that R\&D capital should be augmented with other intangible assets to obtain a measure of knowledge capital as suggested by Clayton et al. (2009).

A second issue is the lag structure in the relationship between innovation/technology and employment. Of the empirical studies included in the meta-analysis, 50\% percent use contemporaneous values of employment and innovation and $31 \%$ use between 1 and 3 lags for technological innovation, with the remaining 19\% using more than 3 lags. The variation in the lag choices appears to be driven by empirical concerns rather than justifications on theoretical grounds. Therefore, further research on the lag structure can enhance the existing knowledge along several paths: (i) identifying the time gap between the introduction of an innovation and the change in employment; (ii) verifying if the innovation's employment effect persists or disappears the lag length increases; and (iii) investigating whether the time gap and degree of persistence differs over time.

A third issue concerns the need for explicit incorporation of market power and creative destruction into the theoretical and empirical models. The Schumpeterian growth literature (Aghion et al., 2014) provides useful insights about the rationale for their inclusion in the growth models and their implications for growth. One way in which the Schumpeterian insights can be incorporated into the derived labor demand model is to allow for interactions between technological innovation and market power. Another way is to treat innovation intensity in the industry or the region not only as a source of knowledge spillovers but also as a source of creative destruction that makes the firm's or the industry's own technology obsolete. 


\section{Related entries from: Handbook of Labor, Human Resources and Population Economics}

- Testing the employment and skill impact of new technologies? A survey and some methodological issues

- Innovation, employment and the business cycle

- New technologies, structural change, the process of development and the labor market

- Effects of ICT Investment on Labor Demand in OECD Countries

- New technologies and the skill mismatch

- Domestic and imported new technologies in developing countries: the employment impact

\section{Index terms}

innovation

process innovation

product innovation

technological change

technology adoption

employment

skill bias / skill-biased

meta-analysis

meta-regression

heterogeneity

selection bias

green revolution 


\section{REFERENCES}

Due to space limitations, primary studies included in the meta-analysis and the systematic review cannot be listed here. The authors acknowledge their debt to all authors of the primary studies and reiterate that full references are available in Ugur and Mitra (2017) and Ugur et al. (2018).

Acemoglu D (1998). Why do new technologies complement skills? Directed technical change and wage inequality. Quarterly Journal of Economics, 113(4): 1055-1089.

Acemoglu D (2002). Directed technical change. Review of Economic Studies, 69(4), 781-809.

Acemoglu D (2003). Patterns of skill premia. Review of Economic Studies, 70(2), 199-230.

Acemoglu D, Autor DH (2011). Skills, tasks and technologies: Implications for employment and earnings. In Card D, Ashenfelter O (eds) Handbook of Labor Economics (Vol. 4, pp. 10431171). Elsevier.

Agarwal B (1981). Agricultural mechanisation and labour use: A disaggregated approach. International Labour Review. 120: 115.

Aghion P, Howitt P (1992). A model of growth through creative destruction. Econometrica, 60(2), 323-351.

Aghion, P., \& Howitt, P. (2006). Appropriate growth policy: a unifying framework. Journal of the European Economic Association, 4(2-3), 269-314.

Aghion P, Akcigit U, Howitt P (2014). What do we learn from Schumpeterian growth theory? In P. Aghion and S. Durlauf (eds), Handbook of Economic Growth, Vol. 2. Amsterdam: Elsevier, pp. 515-563.

Amable B, Gatti D (2004). Product market competition, job security, and aggregate employment. Oxford Economic Papers, 56(4), 667-686.

Annable JE Jr (1971). The Transfer of Technology, Industrialization and The Urban Employment Problem in Low-Income Countries. PhD Thesis: Princeton University.

Autor DH, Dorn D ( 2013). The growth of low-skill service jobs and the polarization of the US labor market. American Economic Review, 103(4), 1553-1597.

Autor, DH, Katz LF, Kearney MS. 2006. The polarization of the U.S. labor market. American Economic Review, 96(2), 198-194. 
Autor DH, Katz LF, Kearney MS (2008). Trends in US wage inequality: Revising the revisionists. The Review of Economics and Statistics, 90(2), 300-323.

Autor DH, Levy F, Murnane RJ (2003). The skill content of recent technological change: An empirical exploration. Quarterly Journal of Economics, 118(4), 1279-1333.

Benavente JM, Lauterbach R (2008). Technological innovation and employment: Complements or substitutes? European Journal of Development Research, 20(2), 318-329.

Berman E, Machin S. (2000). Skill-biased technology transfer around the world. Oxford Review of Economic Policy, 16(3), 12-22.

Berman E, Bound J, Griliches Z (1994). Changes in the demand for skilled labor within U.S. manufacturing: evidence from the annual survey of manufactures. Quarterly Journal of Economics 109(2), 367-397.

Berman E, Bound J, Machin S (1998). Implications of skill-biased technological change: International evidence. Quarterly Journal of Economics, 113(4), 1245-1279.

Berman E, Somanathan R, Tan, HW (2005). Is skill-biased technological change here yet?: Evidence from indian manufacturing in the 1990's. World Bank Policy Research Working Papers, Washington DC.

Bhatia HC, Gangwar AC (1981). Impact of improved technology on farm employment. Indian Journal of Industrial Relations. 16: 623-629.

Bogliacino F (2014). Innovation and employment: A firm level analysis with European R\&D Scoreboard data. EconomiA, 15(2), 141-154.

Caballero RJ, Hammour M (1996) On the timing and efficiency of creative destruction. The Quarterly Journal of Economics. 111: 805-852.

Calmfors L, Driffill J (1988). Bargaining structure, corporatism and macroeconomic performance, Economic Policy, 3(6), 14-61.

Card D, Krueger AB (1995). Time-series minimum-wage studies: a meta-analysis. American Economic Review, 85(2), 238-243.

Chennells L, van Reenen J (2002). Technical change and the structure of employment and wages: A survey of the microeconometric evidence. In Greenan N, L'Horty Y, Mairesse J (eds), Productivity, Inequality and the Digital Economy, Cambridge, MA: MIT Press, pp.175223. 
Chopra, K (1974) Tractorisation and changes in factor inputs: A case study of Punjab. Economic and Political Weekly. 9: A119-A127.

Clayton T, Dal Borgo M Haskel J (2009). An innovation index based on knowledge capital investment: Definition and results for the UK market sector. IZA Discussion Papers, no. 4021.

Costa-Font J, McGuire A, Stanley, TD (2013). Publication selection in health policy research: the winner's curse hypothesis. Health Policy 109 (1), 78-87.

De Klerk M (1984) Seasons that will never return: The impact of farm mechanization on employment, incomes and population distribution in The Western Transvaal. Journal of Southern African Studies. 11: 84-84-105.

Dickersin K, Min YI (1993). Publication bias: the problem that won't go away. Annals of the New York Academy of Sciences, 703(1), 135-148.

Doucouliagos C, Stanley TD (2013). Are all economic facts greatly exaggerated? Theory competition and selectivity. Journal of Economic Surveys, 27 (2), 316-339.

Doucouliagos H, Stanley TD (2009). Publication selection bias in minimum-wage research? A metaregression analysis. British Journal of Industrial Relations, 47(2), 406-428.

Edquist, C., Hommen, L. and McKelvey, M. (2001). Innovation and Employment: Product versus Process Innovation, Cheltenham: Elgar.

Egger M, Smith GD, Schneider M, Minder C (1997). Bias in meta-analysis detected by a simple, graphical test. British Medical Journal, 316, 629-34.

Garmany JW (1978). Technology and employment in developing countries. The Journal of Modern African Studies. 16: 549-564.

Goldin C Katz Lawrence F(2008). The Race Between Education and Technology. Cambridge, MA: Harvard University Press.

Goldin C Katz Lawrence F(2009). The race between education and technology: The evolution of U.S. wage differentials, 1890-2005. National Bureau of Economic Research Working Paper no. 12984.

Goos, M., \& Manning, A. (2007). Lousy and lovely jobs: The rising polarization of work in Britain. The Review of Economics and Statistics, 89(1), 118-133.

Goos M, Manning A, Salomons A (2014). Explaining job polarization: Routine-biased technological change and offshoring. American Economic Review, 104(8), 2509-26. 
Hall BH, LottiF, Mairesse J. (2008). Employment, innovation, and productivity: evidence from Italian microdata. Industrial and Corporate Change, 17(4), 813-839.

Harbord RM Higgins JP (2008). Meta-regression in Stata. Stata Journal, 8(4), 493-519.

Harrison R, Jaumandreu J, Mairesse J, Peters B (2008). Does innovation stimulate employment? A firm-level analysis using comparable micro-data from four European countries. NBER Working Paper No. 14216.

Harrison R, Jaumandreu J, Mairesse J, Peters B (2014). Does innovation stimulate employment? A firm-level analysis using comparable micro-data from four European countries. International Journal of Industrial Organization, 35(July), 29-43.

Inukai I (1970). Farm mechanisation, output and labour input: A case study in Thailand. International Labour Review. 101: 453-473.

Ioannidis JP (2005). Contradicted and initially stronger effects in highly cited clinical research. Jama, 294(2), 218-228.

Katsoulacos, Y. S. (1986). The employment effect of technical change: a theoretical study of new technology and the labour market. University of Nebraska: Wheatsheaf

Katz LF, Autor DH (1999). Changes in the wage structure and earnings inequality. In Ashenfelter O, Card D (eds) Handbook of Labor Economics, vol. 3A, pp. 1463-1555.

Lalwani M (1992). Employment gains of technology adoption - A study of Haryana's dairy farmers. Indian Journal of Agricultural Economics. XIVII: 236-236.

Machin S (2001). The changing nature of labour demand in the new economy and skill-biased technology change. Oxford Bulletin of Economics and Statistics, 63 (s1), 753-776.

Machin S, Van Reenen J (1998). Technology and changes in skill structure: evidence from seven OECD countries. Quarterly Journal of Economics, 113(4), 1215-1244.

OECD (Ongoing). Strictness of employment protection. https://stats.oecd.org/Index.aspx?DataSetCode=EPL_R\&_ga=2.119039503.700660351.1549224124$\underline{661194207.1549224124}$

Pianta M (2000). The employment impact of product and process innovations. In Pianta M, Vivarelli M (eds.), The Employment Impact of Innovation: Evidence and Policy. London: Routledge, pp. 77-95. 
Pianta M (2004). Innovation and employment. In Jan Fagerberg, David C. Mowery, and Richard R. Nelson (eds), The Oxford Handbook of Innovation, Oxford: Oxford University Press, 568-598.

Piva M (2003). The impact of technology transfer on employment and income distribution in developing countries: A survey of theoretical models and empirical studies. ILO Policy Integration Department Working Papers, no. 15. http://www.ilo.org/public/libdoc/ilo/2004/104B09_36_engl.pdf

Romer, P. M. (1990). Endogenous technological change. Journal of political Economy, 98(5, Part 2), S71-S102.

Romer, P. M. (1994). The origins of endogenous growth. Journal of Economic perspectives, 8(1), 3-22.

Sebastian R, Biagi F (2018). The routine biased technical change hypothesis: A critical review. European Commission Joint Research Centre Report, No. JRC113174 (Seville).

Simmons JP, Nelson LD, Simonsohn U (2011). False-positive psychology undisclosed flexibility in data collection and analysis allows presenting anything as significant. Psychological science, 22(11), 1359-1366.

Spiezia V, Vivarelli M, Piva M (2002). Technological change and employment: a twofold theoretical critique and the empirical evidence. Economia e Politica Industriale. Fascicolo 115, 1000-1032.

Stanley TD (2005). Beyond publication bias. Journal of Economic Surveys, 19(3), 309-45.

Stanley TD (2008). Meta-regression methods for detecting and estimating empirical effects in the presence of publication selection. Oxford Bulletin of Economics and Statistics, 70(2), 103127.

Stanley TD, Doucouliagos H. (2007). Identifying and correcting publication selection bias in the efficiency-wage literature: Heckman meta-regression. Deakin University Economics Working Paper Series 2007, 11.

Stanley TD, Doucouliagos H (2014). Meta-regression approximations to reduce publication selection bias. Research Synthesis Methods, 5(1), 60-78.

Stanley TD, Doucouliagos H, Giles M, Heckemeyer JH, Johnston R, Laroche P, Nelson JP, Paldam M, Poot J, Pugh G, Rosenberger RS, Rost K. (2013). Meta-analysis of economics research reporting guidelines. Journal of Economic Surveys, 27(2), 390-394. 
Ugur M, Trushin E, Solomon E (2016). Inverted-U relationship between R\&D intensity and survival: Evidence on scale and complementarity effects in UK data. Research Policy, 45(7), 1474-1492.

Ugur M, Trushin E, Solomon E, Guidi F (2016a). R\&D and productivity in OECD firms and industries: A hierarchical meta-regression analysis. Research Policy, 45(10), 2069-2086.

Ugur M, Mitra A (2017). Technology adoption and employment in less developed countries: A mixed-method systematic review. World Development, 96, 1-18.

Ugur M, Awaworyi Churchill S, Solomon E. (2018). Technological Innovation and Employment in Derived Labour Demand Models: A Hierarchical Meta-Regression Analysis. Journal of Economic Surveys, 32(1), 50-82.

van Reenen J (1997). Employment and technological innovation: Evidence from UK Manufacturing firms. Journal of Labor Economics, 15(2), 255-284.

Vivarelli M (2011). Innovation, employment and skills in advanced and developing countries: a survey of the literature, IDB Publications 61058, Inter-American Development Bank.

Vivarelli M (2012).Innovation, employment and skills in advanced and developing countries: A survey of the literature, Discussion Paper series, Forschungsinstitut zur Zukunft der Arbeit, No. 6291.

Vivarelli M (2013). Technology, employment and skills: an interpretative framework. Eurasian Business Review, 3, 66-89.

Vivarelli M (2014). Innovation, employment and skills in advanced and developing countries: a survey of economic literature. Journal of Economic Issues, 48(1), 123-154. 